\title{
ANÁLISE CRÍTICA DO IDEÁRIO LIBERAL NA TRAJETÓRIA DO CONSTITUCIONALISMO LATINO-AMERICANO
}

\author{
CRITICAL ANALYSIS OF THE LIBERAL IDEA IN THE TRAJECTORY OF \\ LATIN AMERICAN CONSTITUTIONALISM
}

\author{
ANÁLISIS CRITICA DEL IDEAL LIBERAL EN LA TRAYECTORIA DEL \\ CONSTITUCIONALISMO LATINOAMERICANO
}

\author{
SAMUEL MÂNICA RADAELLI \\ https://orcid.org/0000-0002-3343-8338 / http://lattes.cnpq.br/7848518585735152 / samuel.radaelli@ifpr.edu.br \\ Instituto Federal do Paraná- IFPR. \\ Palmas, PR - Brasil. \\ ANTONIO CARLOS WOLKMER \\ https://orcid.org/0000-0003-1861-5305 / http://lattes.cnpq.br/2828972498980275 / acwolkmer@gmail.com \\ Universidade La Salle - UNILASALLE \\ Canoas, RS, Brasil.
}

\begin{abstract}
RESUMO
O desenvolvimento do Constitucionalismo na América Latina, como em todo ocidente, fundamentou-se a partir do Liberalismo. A incidência destes dois movimentos políticos manifestou algumas peculiaridades que refletem o modo como a América Latina consolidou suas instituições e doutrinas políticas. Os processos políticos e os elementos culturais inerentes à trajetória do Constitucionalismo estabelecem práticas de mimetismo e acordos elitistas, os quais são analisados neste texto. Para tanto, a presente pesquisa adota uma metodologia teórico-reflexiva de base sóciojurídica e crítico-descolonial, através de investigação de autores nacionais e estrangeiros. A reflexão sobre este tema constitui-se em quatro momentos: primeiro, a análise da configuração da natureza do individualismo liberal; em seguida, é reconstruída a trajetória do Constitucionalismo latino-americano; depois, busca-se definir as peculiaridades da fundamentação liberal do Constitucionalismo latino-americano; por fim, pretende-se aferir a confirmação do pressuposto que motiva este trabalho, a possibilidade do Constitucionalismo Andino apresentar uma resistência ao paradigma liberal de Constituição.
\end{abstract}

Palavras-chave: América Latina; Constitucionalismo; Liberalismo.

\begin{abstract}
The Latin American Constitutionalism, as in the whole Occident, was based on Liberalism. The incidence of these two political movements manifested some peculiarities which reflect the way Latin America consolidated its institutions and political doctrines. The political processes and the cultural elements inherent in the trajectory of Constitutionalism establish mimicry practices and elitist agreements, that are analyzed in this text. In order to do so, this research adopts a theoretical-reflexive methodology with social-juridical and critical-decolonial basis, through the investigation of national and foreign authors. The reflection about this theme consists of four moments: first, the analysis of the configurations of liberal individualism; second, the Latin American Constitutionalism's trajectory is reconstructed; after that, we seek to define the peculiarities of the liberal foundation of Latin American Constitutionalism; finally, it is intended to confirm the presuppose which motivates this work, that is the possibility of Andean Constitutionalism to present a resistance to the liberal paradigm of Constitution.
\end{abstract}

Keywords: Constitutionalism; Latin America; Liberalism. 


\section{RESUMEN}

El desarrollo del constitucionalismo en la América Latina, como en todo occidente, Fundamento-se a partir del Liberalismo. La incidencia de esos dos movimientos políticos ha manifestado algunas peculiaridades que reflejan la forma en que La América Latina ha consolidado sus instituciones y doctrinas políticas. Los procesos políticos y los elementos culturales inherentes a la trayectoria del Constitucionalismo establecen prácticas de mimetismo de acuerdos a las élites, los cuales son analizados en esto texto. Para eso, la presente investigación adopta una metodología teórico-reflexiva de bases socio-jurídicas y crítico-descoloniales, a través de la lectura de autores nacionales y extranjeros. La reflexión acerca de este tema está constituida en cuatro momentos: primero, el análisis de la configuración de la naturaleza del individualismo liberal; luego se reconstruye la trayectoria del constitucionalismo latinoamericano; Después, buscamos definir las peculiaridades de los fundamentos liberales del constitucionalismo latinoamericano; Finalmente, se pretende verificar la confirmación de la suposición que motiva este trabajo, la posibilidad del Constitucionalismo Andino de resistir a el paradigma liberal de la Constitución.

Palabras clave: América Latina; Constitucionalismo; Liberalismo.

\section{SUMÁRIO}

INTRODUÇAO; 1 INDIVIDUALISMO LIBERAL: SUA NATUREZA; 2 A TRAJETÓRIA DO CONSTITUCIONALISMO LATINO-AMERICANO; 3 LIBERALISMO E CONSTITUCIONALISMO NA AMÉRICA LATINA; 4 RESISTÊNCIAS AO LIBERALISMO CONSTITUCIONAL: CONSTITUCIONALISMO ANDINO; CONCLUSÃO; REFERÊNCIAS.

\section{INTRODUÇÃO}

A compreensão da América Latina necessita ir além da enunciação de fatos históricos, percebendo a expressão de um conjunto de ideias neles refletidas. Com esse intento, faz-se necessário abandonar uma prática comum: a importação de conceitos desenvolvidos em países centrais sem considerar os desafios locais.

A discussão em torno do constitucionalismo latino-americano, ao longo de sua tradição, tem sido a busca por enquadrar uma realidade a determinadas ideias, inobstante o fato de que tal postura não foi feita sem as devidas resistências. Torna-se imperioso estudar estas pretensões teóricas e suas resistências, para que seja possível a prospecção de novos referenciais, adequados à construção de um caminho autêntico, apto a responder aos desafios peculiares destas latitudes.

Ao realizar esta investigação, sabe-se do risco de cair em reducionismos, em razão de serem tratadas de forma conjunta, realidades tão diversas como a dos vários países que compõem a região. No entanto, em meio a estas diferenças, apresentam-se aspectos comuns, os quais determinam o modo de organização e funcionamento do Estado, bem como, dimensionam o alcance e o conteúdo do Direito.

As similitudes existentes entre estes países se originam basicamente do processo colonial vivido por eles. Esse processo estendeu tentáculos culturais para além da 
independência, firmando estruturas de submissão política, social e econômica, que incidem sobre o funcionamento da sociedade latino-americana. Neste âmbito, a discussão em torno do papel do liberalismo na formação do pensamento constitucional regional tem grande relevância, tanto para a compreensão histórica, quanto para o delineamento atual.

A íntima relação entre liberalismo e constitucionalismo, historicamente construída, pautou também a formação dos estados na América Latina na busca por um modelo que desse conta da construção política e institucional e levou a uma aposta mimética que desencadeou tais processos, ora tencionando ora adaptando situações peculiares.

0 presente artigo visa analisar, de forma crítica, a construção do constitucionalismo regional, revelando as concepções liberais que ele materializa, assim como reflete sobre as implicações desses conceitos em um contexto tão diverso do Velho Mundo, onde foi concebido o liberalismo. Tal estudo visa servir de aporte inicial para uma proposta de pensamento constitucional latino-americano, neste âmbito, procura delimitar as pré-compreensões necessárias ao delineamento de um pensamento constitucional original, assentado em bases próprias, as quais, sem nenhum sectarismo, permitam uma contribuição às lutas descoloniais. Necessita-se assim, compreender o papel do liberalismo na formação das concepções inerentes ao tema, tanto em escala universal quanto local.

Esse trabalho aborda, na primeira parte, a afirmação do individualismo proposta pelo Liberalismo, em um segundo momento, examina a trajetória do Constitucionalismo latinoamericano, elencando as características que definem o seu modo de ser, em seguida, é analisada a relação orgânica entre Liberalismo e Constitucionalismo e o seu desenvolvimento na região. Por fim, são postos os elementos que permitam refletir sobre a capacidade do Constitucionalismo Andino desafiar o paradigma liberal e estabelecer novas pautas para a organização política, considerando as necessidades e peculiaridades latino-americanas.

\section{INDIVIDUALISMO LIBERAL: SUA NATUREZA}

As revoluções francesa e estadunidense expressam duas características que vão demarcar a teoria constitucional:

de una parte, la constitución como norma directiva fundamental, que llama a todos os poderes públicos y los individuos a trabajar por el cumplimiento de una empresa colectiva, en teoría para la realización de una sociedad más justa; de otra, la constitución como norma fundamental de garantía, que deja a todas las fuerzas en juego y los individuos el poder de definir sus fines libremente, 
limitando de manera cierta y segura la capacidad de influencia de los poderes públicos, en la línea del gobierno limitado ${ }^{1}$

Na Inglaterra, no final do século XVII, havia uma valorização dos grupos e comunidades, sendo que a autoridade do grupo sobre o indivíduo restringia duramente a liberdade e autonomia do sujeito. 0 indivíduo era controlado pelo grupo a que pertencia e tinha o seu status pessoal vinculado ao grupo, tendo sua individualidade restringida e condicionada. ${ }^{2}$ Como consequência de alterações econômicas, a sociedade se fez mais heterogênea em seus ofícios, artes e profissões, desafiando a organização estática, na qual os sujeitos possuíam um lugar em uma ordem estabelecida.

Com o advento do Estado constitucional, o liberalismo fundamenta também aqueles espaços de liberdade, não necessariamente políticos, que estavam se fortalecendo no seio de uma sociedade que começava a assumir suas características modernas, nela principiando a se formarem o mercado e a opinião pública ${ }^{3}$, dois cenários predominantes no discurso liberal. 0 mercado se configura como uma promessa liberal de libertar o sujeito, cuja percepção origina o ideário de valorização individual enquanto pessoa, dissociada do grupo a que pertence. Como resposta à condição de cerceamento da pessoa, vivido no período, surgem ideias que vão tratar da promoção das liberdades individuais, afirmando a primazia ética do indivíduo frente ao grupo, do valor em si da pessoa humana.

Consequentemente, o liberalismo sustentará que o indivíduo possui direitos dados pela natureza, os quais são condição primeira e fundamental de sua existência, cabendo ao poder estatal construir mecanismo de salvaguarda destes direitos. Tais direitos surgem da compreensão racional do ser humano e da sua condição. Desse modo, a razão firma pouco a pouco sua supremacia na indicação da posição do homem no mundo, sendo para ele a ferramenta fundamental para tornar segura e plena a sua existência.

Prevalecendo a crença de que a razão oferece um caminho mais seguro para a vida em sociedade, ela deve, do mesmo modo que percebe a lógica do funcionamento da natureza, determinar quais são os fundamentos de ordenação social, ou seja, revelar em ambas as dimensões, as leis que ordenam a natureza e a sociedade, afinal, no pensamento de

1 FIORAVANTI, Maurizio. Los derechos fundamentales: apuntes de historia de las constituciones. $6^{\circ}$ Madrid: Trotta, 2009, p.97.

2 FOUCAULT, Michel. A verdade e as formas jurídicas. Rio de Janeiro: Nau, 2003 p. 112.

3 MATTEUCCI, Nicola. Organización del poder y libertad. Historia del constitucionalismo moderno. Madrid: Trotta, 1998, p. 260. 
Montesquieu, lei é "a relação necessária que deriva da natureza das coisas." 4 Sem dúvida, ser liberal no século XIX significou defender, inseparavelmente, fatores como a rescontrução da autoridade do Estado soberano e, ao mesmo tempo, negar-lhe todo o poder sobre o indivíduo. Pode-se dizer, em síntese, queem uma constituição liberal tem-se a garantia de direitos fundamentais, mas a mesma não pode impor ao Estado soberano diretivas para sua ação propositiva, pois:

O desejo de terminar a revolução, ou seja, de afastar a figura ameaçadora do soberano, é marcante nas constituições liberais do século XIX. A questão da soberania é omitida, está oculta, em tese, resolvida. Ao equilibrarem-se entre rei e parlamento, as constituições liberais reduziram seu espaço de abrangência, buscando sistematizar as relações entre órgãos constitucionais e garantir os direitos individuais dos cidadãos. No século XIX, constituições perderam seu caráter revolucionário originário de direção fundamental para a construção de uma nova sociedade. 0 modelo constitucional liberal, inspirado em Montesquieu, busca garantir a forma de governo moderada balanceada, com tendência de equilíbrio dualista entre monarca e parlamento. ${ }^{5}$

Por ser uma doutrina marcada por sua flexibilidade e adaptabilidade, descrevendo um panorama geral da sua incidência constitucional, a qual tende a assumir matizes peculiares em cada país de acordo com circunstâncias geográficas e temporais, torna-se uma tarefa difícil e sujeita a induções e análises demasiado casuístas. Nesse âmbito, no entanto, parece possível estabelecer uma classificação, presente ao menos na construção mais originária do liberalismo, apresentada em duas matrizes: a tradição inglesa, vinculada às preocupações com a limitação do poder estatal e, em outra frente, uma tradição francesa, na qual predominam esforços de fortalecimento estatal com vistas a organizar a igualdade ante à lei. ${ }^{6}$

Dessa forma, as forças burguesas vão domesticando o constitucionalismo, bem como as instituições por ele forjadas. Soma-se a isso, o fato de que as garantias mais caras aos liberais foram sedimentadas no Código Civil, fator que colabora para o declínio das constituições e ascensão dos códigos. O primado da Constituição poderia significar o primado da política, assim, na lógica burguesa, tornou-se necessário conter a força do poder constituinte, o qual necessita ser dissolvido para que as instituições se organizem de acordo com os interesses burgueses. Por

4 MONTESQUIEU, Charles de Secondat, Barão de. O espírito das leis. Apresentação Renato Janine Ribeiro; tradução Chistina Murachco. São Paulo: Martins Fontes, 1996, p. 11.

5 BERCOVICl, Gilberto. Soberania e Constituição: para uma crítica do constitucionalismo. São Paulo: Quartier Latin, 2008.p.168.

6 MERQUIOR, José Guilherme. Liberalismo antigo e moderno. São Paulo: É Realizações, 2014. 
conta disso, volta- se para a consolidação da propriedade, a naturalização do mercado, a busca pela paz e a segurança jurídica.

Tendo a burguesia alcançado sua ascensão por meio de processos revolucionários, passados esses eventos, alterou completamente sua forma de agir. Obtida a ruptura por ela desejada, tratou de buscar a conservação do status que havia conseguido: "o pensamento jurídico-político europeu do século XIX, em sua imensa maioria, vai se manifestar contra o poder constituinte do povo [...] o liberalismo do século XIX isola e marginaliza a teoria do poder constituinte, associada ao terror jacobino"7.

Se, inicialmente, as revoluções burguesas são influenciadas pelos ideais de soberania popular de Rousseau, pouco a pouco, migram para as propostas de organização institucional do poder, através da sua partição. Assim, adota-se a convicção teórica de que é melhor o governo das leis que dos homens. Também proposta por Montesquieu, tal perspectiva serve muito bem ao ideal elitista de desmobilizar e neutralizar as forças populares utilizadas para a derrubada do antigo regime.

No processo de dissuasão e controle das massas revoltosas, a burguesia parte em seguida para a valorização da lei civil e da caraterização tradicional-racional de construção do Direito. Com a codificação da legislação civil, o conhecimento e a prática jurídica foram resumidas a ele, sendo que, na França, a Constituição foi relegada a um plano político, tendo a sua natureza jurídica negada por mais de dois séculos. ${ }^{8}$ Esse caso retrata bem a guinada estratégica do liberalismo, agindo no intuito de consolidar um Direito em que predominassem os seus valores mais importantes, os quais beneficiavam apenas uma pequena parcela da sociedade.

\section{A TRAJETÓRIA DO CONSTITUCIONALISMO LATINO-AMERICANO}

A Constituição de Cádiz (1812) teve influência na formação do constitucionalismo latinoamericano, sendo, inclusive, realizada com a presença de constituintes do Novo Mundo. Além disso, ela foi pioneira no mundo ibero-americano em estabelecer as relações políticas sobre

7 BERCOVICI, Gilberto. Soberania e Constituição: para uma crítica do constitucionalismo. São Paulo: Quartier Latin, 2008, p. 169.

8 DALLARI, Dalmo de Abreu. A constituição na vida dos povos: Da idade Média ao século XXI. São Paulo: Saraiva, 2010, p. 109. 
novas bases, pautadas majoritariamente pelo iluminismo e o liberalismo. Neste âmbito, buscou desmontar o absolutismo e a sociedade dividida em estamentos.

Sua redação trazia disposições que aboliam as instituições senhoriais, a Inquisição, o tributo pago pelas comunidades de índios e o trabalho forçado. Suas disposições voltaram-se para a criação de um Estado unitário, orientado para igualdade ante a lei, com limites à autoridade monárquica, sustentando o poder político do parlamento. Seguindo as bases liberais e iluministas que a inspira, a Constituição de Cádiz fortaleceu e ampliou o sufrágio, sem, contudo, torná-lo universal, uma vez que descendentes de africanos não poderiam votar; também dispensou o censo econômico ou cultural, inovando, mesmo para as matrizes tradicionais, notadamente, a francesa e a americana. ${ }^{9}$

Sua incidência é nítida nas seguintes constituições: da Gran Colombina (1821), de Nova Granada $(1830,1832)$, da Venezuela (1830), do Peru $(1823,1828)$, da Argentina (1826), do Uruguai (1830), do Chile (1828) e do México (1824), sendo esta a mais divergente. Dessa forma, - Constitucionalismo latino-americano bebeu de duas vertentes básicas: o modelo descentralizado de Cádiz, apoiado em geral pelas elites civis; e o modelo napoleônico, apoiado majoritariamente pelo exército, destacando se Simon Bolívar entre seus defensores. ${ }^{10}$

Contudo, a influência de Cádiz acabou se reduzindo a uma idealização formalista:

Seguindo o modelo da constituição espanhola de 1812, a elite criolla de muitos países tentou estabelecer um sistema centralista, enfeitado com os ornamentos do constitucionalismo. (....) revelou-se uma importante diferença entre as tarefas daqueles que escreveram a Constituição de Cádiz e dos autores das cartas hispano-americanas dos anos posteriores. Em Cádiz, os liberais espanhóis se preocuparam em circunscrever o poder do rei absolutista, convertendo-o num monarca constitucional. Na América espanhola, porém, o mesmo modelo constitucional foi usado numa tentativa mais de fortalecer do que de enfraquecer a autoridade central tal como fora constituída anteriormente nas primeiras cartas hispano-americanas. Além disso, a maioria das constituições hispano-americanas fizeram importante acréscimo ao modelo de Cádiz: permitiram aos presidentes o uso dos poderes extraordinários em momentos de ameaça externa ou perturbação interna. ${ }^{11}$

A cidadania é usada como mecanismo para a imposição da civilização em nosso continente. Nesse contexto, entenda-se civilização como "a consciência que o ocidente tem de si mesmo. Com essa palavra, a sociedade ocidental procura descrever o que lhe constitui o

9 SAFFORD, Frank. Política, ideologia e sociedade na América espanhola do pós-independência. In: BETHEL, Leslie. História da América Latina: da independência a 1870, Vol. III. São Paulo: Imprensa Oficial do Estado, 2001, p. 344.

10 Idem, ibidem.

11 SAFFORD, Frank.op.cit., p. 346. 
caráter especial e aquilo de que se orgulha: o nível de sua tecnologia, a natureza de suas maneiras"12. Haja vista que está temática esta envolta na questão da posição dos indígenas, escravos, negros alforriados e mestiços na sociedade. ${ }^{13}$

O caráter mimético da experiência constitucional latino-americana configurou, assim, não pela apreensão analítica de uma experiência de países centrais, mas sim por reiteradas práticas que propunham transposição de institutos. Tal atitude ocorreu, ainda, sem o exame da adequabilidade, tanto do ponto de vista político, quanto na perspectiva jurídica e cultural. Esta experiência constitucional inventou uma tradição ${ }^{14}$ que necessita ser revisitada, com o propósito de superação de desigualdades inerentes à condição política e social dessa sociedade, paradoxalmente negadas no texto constitucional.

Assim, embora outras formas possíveis de vida tenham sido descobertas com a expansão europeia, não existiu uma incorporação da ideia de que estas formas de vida também estivessem assentadas sobre modelos organizativos igualmente válidos. ${ }^{15}$ As condições de colonialidade epistêmica formaram uma prática de mimetismo constitucional, pelo qual as experiências constituintes buscam sempre espelhar o melhor do constitucionalismo dos países centrais. Tal mimetismo é assim expresso por Dussel:

En América Latina, la costumbre de pretender copiar la mejor Constitución del momento (creada adecuadamente para otra comunidad en otro momento político), impulso a los políticos y patriotas a pretender cumplir una función imposible, la de meter la realidad de la propia comunidad política en modelo extraño, en un estrecho corsé. El resultado está a la vista. Nunca se alcanzó hasta el presente un estado de derecho, porque las instituciones ( $\mathrm{y}$ el mismo derecho) no surgieron de prácticas pre-existentes registradas en la experiencia como exitosas políticamente a las que había que institucionalizar para fijarlas

12 ELIAS, Norbert. O processo civilizador: uma história dos costumes (v.1). Rio de janeiro: J. Zahar, 1994, p.23. Na mesma linha, "sobretudo, após a revolução francesa, a palavra civilização, que designa um processo, tornou-se quase sintoma com a aceitação da ideia moderna de progresso, confirmando-se, assim, algo que sua emergência já potencializava, a saber: a sua transformação num substituto laicizado da religião e numa espécie de "parusia da razão". CATROGA, Fernando de almeida. Caminhos do fim da história. Coimbra: Quarteto editora, 2003, p. 94.

13 GAUER, Ruth Maria Chittó. Constituição e cidadania. Porto Alegre: Livraria do Advogado, 2014, p. 17 62.

14 "por tradição inventada, entende-se um conjunto de práticas, normalmente reguladas por regras tácitas ou abertamente aceitas, tais práticas, de natureza real ou simbólica, visam inculcar certos valores e normas de comportamento através da repetição, o que implica, automaticamente, uma continuidade em relação ao passado". HOBSBAWM, Eric. Introdução: a invenção das tradições. In: HOBSBAWM, Eric, RANGER, Terence O.(Org.). A invenção das tradições. Tradução: Celina Cardim Cavalcante. Rio de Janeiro: Paz e Terra, 1984, P.9.

15 ANDERSON, B. Nação e Consciência Nacional. São Paulo: Editora Ática, 1989. 
como permanentes para hacer posible la gobernabilidad estable a la que aspira todo orden político ${ }^{16}$.

Tal vivência constitucional formou uma tradição ${ }^{17}$ que necessita ser revisitada, com o propósito de superação de desigualdades inerentes às condições política e social dessa sociedade, paradoxalmente negadas no texto constitucional.

\section{LIBERALISMO E CONSTITUCIONALISMO NA AMÉRICA LATINA}

O liberalismo na América Latina teve seu desenvolvimento inicial coincidindo com os processos de independência. Sua trajetória ocorreu em diferentes cadências, com múltiplas formas de se manifestar em cada país, matizado por diversas circunstâncias tanto internas como externas e, principalmente, com um conjunto de concessões às configurações políticas próprias de cada sociedade, de forma que não se efetivou por um padrão uniforme. A implementação do liberalismo na construção do Estado-Nação na América Latina não foi realizada sem que houvesse resistência. As tensões em torno da presença do liberalismo e as tentativas constitucionais de sua refutação ou atenuação são traços indeléveis da sua construção histórica, os quais ainda hoje são um desafio para qualquer processo constituinte.

Tratando do tema, Aguilar Rivera o define como o "experimento constitucional atlântico" do século XIX, sendo os estados latino-americanos recém- independentes um teste, colocando à prova a capacidade do liberalismo sedimentar-se em sociedades diversas das originárias. Seguindo a senda do mesmo autor, as propostas liberais dos séculos XVIII e XIX careciam da experimentação das inovações que esta teoria propunha. Dessa maneira, a “América Latina representa el gran experimento constitucional pos-revolucionario", contudo, “[...] rara vez se reflexiona sobre su importancia para la teoría liberal."18

Discorrendo ainda, Aguilar Rivera sustenta que a presença do liberalismo deu-se mediante várias resistências, tendo ele se firmado como predominante, embora não absoluto. Não existiu, segundo ele, nenhuma sociedade que se contrapôs ao liberalismo de forma vigorosa, embora, em todas, isso realizou-se mediante concessões que atenuaram seu caráter original. No

16 DUSSEL, Enrique. Política de la liberación. Volume II. Arquitectónica. Madrid: Trotta, p. 293.

17 HOBSBAWM, Eric. Introdução: a invenção das tradições. In: HOBSBAWM, Eric; RANGER, Terence(Org.). op.cit., p.9.

18 AGUILAR RIVERA, José Antonio. En pos quimera. Reflexiones sobre el experimento constitucional atlántico. México-DF: Fondo de Cultura Económica, 2000, p. 24. 
mesmo sentido, aponta Gargarella, "si la base del constitucionalismo norteamericano fue casi plenamente liberal (en cuanto al origen y contenidos del texto constitucional) en Latinoamérica dicha base fue resultado habitual de un acuerdo liberal-conservador." 19

Esse surpreendente pacto liberal-conservador ocorreu em razão de que, ambos grupos tinham, inobstante suas enormes diferenças, muitos objetivos em comum. Seu principal ponto de discórdia se dava nos temas religiosos: enquanto uns queriam o estabelecimento de uma ordem favorável ao império da religião, outros, por diversas razões, muitas delas de ordem econômica, criticavam tal postura, havendo até aqueles que professavam o ateísmo e, por conta disso, postulavam uma ordem constitucional mais aberta. Liberais e conservadores apresentavam diferenças, também, em relação ao nível de concentração da autoridade nacional e política. Para além destas discrepâncias, houve um enorme campo de convergência. Tanto liberais como conservadores tinham interesse na defesa da propriedade, ameaçada pelas demandas crescentes de grupos politicamente cada vez mais exigentes. Nesse sentido, ambas as colorações políticas se mostravam temerosas das consequências resultantes do acesso ativo das massas ao sistema de tomada de decisões.

O resultado dos acordos que ocorreram entre liberais e conservadores envolveu a adoção de um regime constitucional que combinou traços valorizados por ambos os grupos. Assim, resulta um produto híbrido: um sistema de tipo liberal, organizado a partir da ideia americana de "freios e contrapesos", mas desequilibrado, devido a uma autoridade executiva mais poderosa, como desejavam os setores conservadores. Já, os sistemas jurídicos geralmente consagravam a tolerância religiosa, mas, como no caso argentino, deixavam um lugar privilegiado ao catolicismo. ${ }^{20}$

Partindo de um fundo pretensamente liberal, forma-se o modelo clássico de Estado e Constituição, configurado como liberal-oligárquico, possuindo como principais características:

expresa y refleja la situación de dependencia e en el orden mundial y la división internacional del trabajo estructurados por Europa occidental y Estados Unidos; la economía y el tipo de desarrollo primario-exportador; una sociedad jerarquizada y rígida; una cultura híbrida, de cosmopolitismo y nacionalismo. El estado oligárquico se estructura a partir de condiciones de conflicto y

19 GARGARELA, Roberto. Los fundamentos legales, de la desigualdad, el constitucionalismo en América. Madrid: Siglo XXI, 2005, p.217.

20 GARGARELA, Roberto. Op.cit., p.208. 
desequilibrio generalidad, a través de un largo período de guerras externas y civiles, de anarquía y caudillismo. ${ }^{21}$

Outra referência ao sincretismo liberalismo-conservadorismo é a vinculação entre liberalismo e patrimonialismo, "que de um lado permitiria o "favor", o clientelismo e a cooptação; de outro, introduziria uma cultura jurídico-institucional marcadamente formalista, retórica e ornamental. (...)Além de seus aspectos conservadores, individualistas, antipopulares e não populares democráticos, o liberalismo brasileiro deve ser visto igualmente por seu profundo traço ‘juridicista'. Naturalmente, a adequação esdrúxula de concepções ideológicas distintas, internalizada a um cenário autoritário e excludente, acabou gerando a especificidade de um “liberalismo-conservador" também nas formas tradicionais de controle social. Ora, enquanto o ideário conservador exalta a tradição, a hierarquia, a formalidade normativa e a distinção social, o liberalismo faz a defesa do equilíbrio, da conciliação, da ordem sem conflito, da isenção de valores e da individualidade."22

Desse modo, este sincretismo teve sua implementação de forma negociada com interesses locais. Por sua vez, o caso brasileiro é um exemplo, expresso pela manutenção da escravidão por quase todo o período imperial ao longo do século XIX. Já, com a República, efetiva-se "o contínuo produto da conciliação-compromisso entre o autoritarismo social modernizante e o liberalismo burguês conservador." ${ }^{23}$ Seguindo o propósito de usar princípios universais aplicáveis a todos os governos representativos, o liberalismo, no continente latinoamericano, não logrou êxito no seu intento de governos estáveis, percorrendo um terreno tão diverso do original, pois sua incidência, no período inicial, não colaborou com o desenho institucional de Estados nascentes, tendo inclusive complicado tal tarefa. ${ }^{24}$

Os liberais latino-americanos manifestaram, via de regra, uma postura europeizante, disposta a buscar saídas universais para alçar o desenvolvimento das sociedades regionais. No século XIX, no entanto, percebe-se o desenvolvimento de um “espírito americano”, voltado para

21 KAPLAN, Marcos. El estado y la teoría política y constitucional en América Latina. In: GONZALEZ CASANOVA, Pablo. El estado en América latina teoria y prática.México, DF: SigloVeinte Uno editores: 1990, p.71.

22 WOLKMER, Antonio Carlos. História do direito no Brasil. 5ed. Forense: Rio de Janeiro. 2012, p. 108

23 WOLKMER,Antonio Carlos. Constitucionalismo e direitos sociais no Brasil. Acadêmica: 1989, p.1989, p. 35.

24 AGUILAR RIVERA, José Antonio. En pos quimera. Reflexiones sobre el experimento constitucional atlántico. México:DF, 2000, p. 15-40. 
as pautas desenvolvidas no EUA. Passa-se a ter outro foco de influência, tendo especial interesse pelas novidades constitucionais de lá oriundas, em especial o federalismo. ${ }^{25}$

É inegável a incidência do liberalismo na construção da ordem institucional democrática, principalmente na consolidação da divisão dos poderes, na formatação de bases republicanas e no desenvolvimento do controle de constitucionalidade. Outro grande mérito do liberalismo na América Latina foi a abolição da escravatura, realizada antes da metade do século XIX, excetuando-se apenas Brasil e Cuba. No entanto, a adoção de pressupostos liberais foi feita de modo a tornar natural as formas de democracia e direitos fundamentais nela contidas. Em razão disso, criou-se um ambiente de referenciação circular que impediu um diálogo sobre estes temas fora do próprio liberalismo.

Além disso, o liberalismo identificava o Estado como causador de determinados males que podiam ser causados por interesses privados particulares, portanto, sendo necessário estabelecer mecanismos de defesa não apenas contra o Estado. Do mesmo modo, o liberalismo, enquanto valorização da autonomia do sujeito, não pensou em elementos que permitissem condições para que esta autonomia de fato acontecesse.

Lo cierto es que el liberalismo nunca realizo mayores esfuerzos para demostrar que existen razones para considerar natural el estado de cosas distributivo que defienden. Simplemente, sus defensores asumen como neutral o dado un cierto estado de cosas al que consideran valioso. Y, más aún, derivan a partir de dicho supuesto injustificado un supuesto adicional, conforme al cual la definición de un cierto estado de cosas como natural constituye una razón para considerar-lo, en principio, inmodificable o sólo modificable en casos excepcionales. Esto es, asumen que es deber del poder público no intervenir sobre ese estado de cosas, para intentar remediar o poner límite a las malas consecuencias que de allí pueden seguirse. En tal sentido, los liberales se negaron a reconocer que el estado no era neutral sino que, de algún modo significativo, se encontraba tomando partido al dejar que la propiedad quedase concentrada en pocas manos (como ocurrió con la apropiación de los ejidos por los sectores más poderosos, durante el régimen de López en Nueva Granada, o como ocurrió en la Argentina, luego de dictada la ley de enfiteusis rivadaviana). ${ }^{26}$

0 individualismo inerente ao liberalismo concebia cada sujeito em luta solitária pela satisfação de suas múltiplas necessidades, percepção que choca-se diretamente com o espírito comunitário das populações originais de Nuestra América. Tal contraste marca decisivamente o

25 CARBO POSADA, Eduardo; JAKSIC, Iván . Naufragios y sobrevivencias del liberalismo latino-americano. In: CARBO POSADA, Eduardo; JAKSIC, Iván. Liberalismo y poder: Latinoamérica in siglo XIX. Santiago: Fondo de cultura Económica, 2011, p. 34

26 GARGARELA, Roberto. Los fundamentos legales, de la desigualdad, el constitucionalismo en la América. Madrid: Siglo XXI, 2005, p.220-221. 
modo contraditório de como foi formada esta solidariedade social. 0 individualismo liberal exacerba o culto às noções de sujeito de direito, pessoa humana em uma visão atomizada, nas quais as relações eram pautadas por uma visão de trocas e interações individuais. Tal compreensão, respaldada por uma visão moderna do sujeito, foi atacada quando foram construídas garantias para grupos e comunidades. Dessa forma, é desafiada a noção liberal de sujeito de direito, na qual não mais se prima pela produção de direitos ao indivíduo, vista de forma isolada, passando para uma percepção coletiva que visualiza o sujeito como pertencente a um determinado grupo com o qual compartilha uma determinada realidade.

\section{RESISTÊNCIAS AO LIBERALISMO CONSTITUCIONAL: CONSTITUCIONALISMO ANDINO}

Uma ordem constitucional deveria ter como esteio a sociedade civil. As constituições liberais foram obstáculos à realização desta tarefa, como explicita Aguilar Rivera: “Un Estado liberal compuesto por individuos, constitucional y limitado pero oligárquico, no lo era. La constitución liberal, que excluía mecanismos para preservarse en las crisis, era una quimera que prometía a la vez libertad e orden". ${ }^{27}$

A vinculação genética entre liberalismo e constitucionalismo, tão referida em diversos estudos na América Latina, teve desde o início uma relação de tensão. Inicialmente, a aplicação do modelo de estado liberal sofreu a resistência do bonapartismo defendido por Bolívar, como já foi anteriormente exposto. Um segundo momento de crítica e resistência ao liberalismo constitucional, ainda no século XIX, deu-se com o Constitucionalismo Radical.

No início do século $X X$, o Constitucionalismo Social representou outro momento de enfrentamento ao Liberalismo. A constituição mexicana de 1917 foi um momento de atenuação da compreensão liberal, por meio de mecanismos constitucionais que preconizavam a proteção do trabalho e garantia da propriedade camponesa. Dessa forma, refreou princípios liberais como a livre iniciativa, a propriedade privada e a soberania da vontade contratual. ${ }^{28}$

Por fim, o início do Século XXI foi palco de processos constituintes vividos pelo Equador (2008) e pela Bolívia (2009), engendrando a tendência denominada de Constitucionalismo

27 AGUILAR RIVERA, José Antonio. En pos quimera. Reflexiones sobre el experimento constitucional atlántico. México: DF 2000, p. 201.

28 SAYEG HELÚ, Jorge. El constitucionalismo social mexicano: la integración constitucional de México (1808-1988). México-DF: Fondo de Cultura Económico, 1996, p. 585-724. 
Pluralista Andino. Tais rupturas na tradição constitucional latino-americana caracterizam-se por priorizar a construção de um modelo próprio de Estado e de sociedade, disposto a enfrentar as mazelas existentes nestas sociedades, decorrentes de um passado colonial, bem como do gerenciamento segregador das populações originárias realizado por elites oligárquicas dominantes. Assim, o Constitucionalismo Pluralista Andino permite romper com as propostas trazidas pela tradição constitucional liberal, enfocando a perspectiva do pluralismo jurídico e as alternativas advindas dessa opção, na realização do ideário de transformações propostas por seus sujeitos sociais emergentes, dentre os quais os povos originários.

Com o Constitucionalismo Pluralista Andino, apresentam-se novas possibilidades de reconstrução política, à medida que sua concepção e construção se deram por processos constituintes genuinamente populares. Contudo, não por uma participação em moldes liberais, mas sim, em uma perspectiva comunitária na qual o povo é visto como membro de um grupo com matrizes étnicas e antropológicas próprias.

Nessa perspectiva, abre-se um novo horizonte de organização social, que se apresenta apto a superar realidades históricas de exclusão. Afinal, este cenário de exclusão se consolidou a partir de processos de marginalização de determinados grupos, em processo de negação do autêntico modo de ser latino-americano.

Nas novas Cartas, o reconhecimento e a valorização dos grupos historicamente negados concretizam-se tanto no âmbito da afirmação textual de aspectos antropológicos como na construção de instrumentos constitucionais que permitem operacionalizar tais elementos. No esforço de operacionalização, destacam-se o respeito ao direito e à jurisdição indígena, a garantia de representação política por critérios como gênero e grupo étnico, bem como, a garantia à apropriação pública das riquezas naturais, a qual se dá tanto da propriedade quanto na destinação dos lucros auferidos. Do objetivo de reconstruir o modelo democrático, surge a necessidade de reconhecer as esferas do poder comunitário para além dos espaços formais existentes, constituindo-se, assim, uma dupla instância: institucional e extra-institucional. ${ }^{29}$

A história dos processos constitucionais na América Latina, até então, reflete a colonialidade $^{30}$ nas suas mais variadas formas (econômica, política, cultural e epistemológica),

29 PISARELLO, Gerardo. Estado de derecho y crisis de la soberanía em américa latina: algunas notas entre la pesadilla y la esperanza. In: estado de derecho, concepto, fundamentos y democratización em América Latina. México-DF: Siglo XIX, 2002, p. 296.

30 MIGNOLO, Walter. La idea de América latina: la herida colonial y la opción decolonial. Barcelona: Gedisa, 2005; QUIJANO, Anibal. Colonialidad del poder, eurocentrismo y América latina. In: LANDER, 
bem como a negação da sua alteridade ${ }^{31}$, na medida em que é fruto de práticas de importação de conceitos eurocêntricos, que negam as diferenças existentes entre as nações, afirmando a universalidade de seus preceitos. Tal fato, historicamente tem favorecido uma relação de dominação euro-americana sobre os demais países.

Em função da totalidade e da colonialidade constitucionais, as vivências peculiares dos povos do "novo mundo" foram negadas. Exemplo típico é a questão indígena, a qual, até então, teve um tratamento constitucional cujo pressuposto era a tutela desses povos, sem garantias de autonomia e reconhecimento de sua cultura. Os processos políticos dos últimos quinze anos na região, que desaguaram em novas constituições, contemplam um universo de realidades juridicamente desconsideradas nos textos tradicionais de constitucionalidade liberal, tendo por objetivo consolidar novos mecanismos jurídico-políticos adequados a esta realidade.

0 pluralismo jurídico acolhido nestes textos constitucionais tende a colaborar com a afirmação da alteridade latino-americana e do giro descolonial. Por consequiência, traz a possibilidade de um novo movimento constitucional, único por expressar o ser latino-americano tão negado ao longo dos séculos. Assim, surge no âmbito da teoria constitucional um novo momento, no qual se vislumbra a possibilidade de superação das estruturas opressivas consolidadas por um horizonte colonial, firmado através de ideários constitucionais importados e substancialmente indiferentes à realidade latino-americana.

Essas novas Cartas Magnas constroem estruturas jurídicas voltadas para os desafios sociais, econômicos, políticos, ambientais e culturais típicos da América Latina, para as quais não basta a importação de modelos constitucionais decorrentes do universalismo europeu ${ }^{32}$, que não reconhece outras realidades e que se impôs na região quando da construção dos projetos constitucionais.

O constitucionalismo latino-americano necessita reconstruir os seus textos, mas isso não basta, faz-se necessário, também, renovar o pensamento constitucional. Em verdade, na

Edgardo. La colonialidad del saber: eurocentrismo y ciencias sociales perspectivas latinoamericanas. Caracas: Clacso, 2000.

31 DUSSEL. Enrique. Filosofia da libertação. São Paulo: Loyola, 1983; DUSSEL. Enrique. 1942: o encobrimento do outro. Petrópolis: Vozes 1993;ZIMMERMANN, Roque. América latina- o não-ser: uma abordagem filosófica a partir do pensamento de Enrique Dussel (1962-976). $2^{\circ}$ Ed. Petrópolis: Vozes, 1987

32 O universalismo europeu sustenta a idéia de que a tutela é uma forma de desenvolver povos atrasados e de que o império das potências sobre o globo seria inevitável; e que para as outras nações não haveria escolha e deveriam submeter-se a elas. WALLERSTEIN, Immanuel. 0 universalismo europeu: a retórica do poder. São Paulo: Boitempo, 2007. 
especificidade do constitucionalismo pluralista dos Andes, este se constitui por cartas transformadoras, mas, que pode representar apenas um novo simbolismo ineficaz e ilusório.

\section{CONCLUSÃO}

Com a análise do percurso do Liberalismo e sua influência marcante no constitucionalismo da América Latina, verifica-se que a organização do Estado, a definição e extensão da democracia, juntamente com a afirmação de direitos, tarefas tipicamente constitucionais, apresentam um cenário de desafios no tocante à apropriação popular desses espaços e mecanismos. A necessidade mais premente é produzir um pensamento social descolonial, sem ele, todos os demais intentos tendem a ser respostas exógenas para problemas nacionais, os quais deixam um saldo de inefetividade.

Tido como o grande experimento constitucional atlântico ${ }^{33}$, a construção do constitucionalismo latino-americano pode ser entendida como expressão de um "liberalismo constitucional atenuado" 34 . Trata-se da consolidação de uma proposta liberal que leva a cabo sua implementação, abarcando propostas que não fazem parte, ou até contrárias ao ideário liberal. Embora as atenuações e os sincretismos sofridos, o liberalismo mantém uma influência medular na estrutura e na compreensão constitucional latino-americana.

Além das históricas buscas por uma ruptura com esse modelo de constitucionalidade liberal-individualista, soma-se a construção de um novo constitucionalismo latino-americano de tipo pluralista e descolonial. Nele apresentam-se outras alternativas de reconstrução política, à medida que tais concepções e construções ocorreram por processos constituintes referendados pela participação popular. Portanto, não mais pelo perfil de tradição elitista, marcada por dinâmicas de indução e representação, mas por práticas de atuação comunitária e participativa, nas quais, o sujeito, agora coletivo, é partícipe de um grupo com matrizes étnicas e antropológicas próprias.

33 AGUILAR RIVERA, José Antonio. En pos quimera. Reflexiones sobre el experimento constitucional atlántico. México- DF: Fondo de cultura Económica, 2000.

34 MOTA, Aurea. Estado e Liberalismo na América latina: processos contemporâneos à luz da história. In: Anais $37^{\circ}$ Encontro Anual da Anpocs. Disponível em: anpocs.org/portal/índex.php. Acesso em $10 / 10 / 2016$. 
Enfim, dentre os esforços estabelecidos por esta nova configuração constitucional estão: a superação dos mecanismos de exclusão oriundos de uma visão individualista da democracia e dos direitos; o reconhecimento das interações interculturais; e a reconfiguração estatal e jurídica a partir de propostas transformadoras como a plurinacionalidade, a interculturalidade e o pluralismo jurídico.

\section{REFERÊNCIAS}

AGUILAR RIVERA, José Antonio. En pos quimera. Reflexiones sobre el experimento constitucional atlántico. México- DF: Fondo de cultura Económica,2000.

ANDERSON, B. Nação e Consciência Nacional. São Paulo: Ática, 1989.

BAUTISTA ALBERDI, Juan. Bases y puntos de partida para a organización política de la republica Argentina. Buenos Aires: Estampa, 1982.

BERCOVICI, Gilberto. Soberania e Constituição: para uma crítica do constitucionalismo. São Paulo: Quartier Latin, 2008.

CARBO POSADA, Eduardo; JAKSIC, Iván Naufragios y sobrevivencias del liberalismo latinoamericano. In: CARBO POSADA, Eduardo; JAKSIC, Iván. Liberalismo y poder: latinoamerica in siglo XIX. Santiago: Fondo de cultura Económica, 2011.

CESAIRE, Aimé. Discurso sobre o colonialismo. Trad. Anísio Garcez Homem. Florianópolis: Letra Contemporâneas. 2010.

DALLARI, Dalmo de Abreu. A constituição na vida dos povos: Da Idade Média ao século XXI. São Paulo: Saraiva, 2010.

DUSSEL, Enrique. Política de la liberación. Volumen II. Arquitectónica. Madrid: Trotta, p. 293.

FANON, Frantz. Os Condenados da terra. 2. ed. Rio de Janeiro: Civilização Brasileira, 1999.

FIORAVANTI, Maurizio. Los derechos fundamentales: apuntes de historia de las constituciones. $6^{\circ}$ Madrid: Trotta, 2009.

FOUCAULT, Michel. A verdade e as formas jurídicas. Rio de Janeiro: Nau, 2003.

GARGARELA, Roberto. Los fundamentos legales, de la desigualdad, el constitucionalismo en la América. Madrd: Siglo XXI, 2005.

GROS ESPIELL, Hector. El constitucionalismo latinoamericano y la codificación en el siglo XIX. Anuário Iberoamericano de justicia constitucional. número 6, jan/dez 2002.

HOBSBAWM, Eric. Introdução: a invenção das tradições. In: HOBSBAWM, Eric, RANGER, Terence (Orgs.). A invenção das tradições. Tradução: Celina Cardim Cavalcante. Rio de Janeiro: Paz e Terra, 1984.

KAPLAN, Marcos. El estado y la teoría política y constitucional en América Latina. In: GONZALEZ CASANOVA, Pablo. El estado en América latina teoría y práctica. México, DF: Siglo Veintiuno, 1990. 
MATTEUCCI, Nicola. Organización del poder y libertad. Historia del constitucionalismo moderno. Madrid: Trotta, 1998.

MERQUIOR, José Guilherme. Liberalismo antigo e moderno. São Paulo: É Realizações, 2014. MIGNOLO, Walter. A idea de américa latina: la herida colonial y la opción decolonial. Barcelona: Gedisa, 2007.

MONTESQUIEU, Charles de Secondat, Barão de. 0 espírito das leis. Apresentação Renato Janine Ribeiro; tradução Chistina Murachco. São Paulo: Martins Fontes, 1996.

SAFFORD, Frank. Política, ideologia e sociedade na América espanhola do pós-independência. In: BETHEL, Leslie. História da América Latina: da independência a 1870, Vol. III. São Paulo: Imprensa Oficial do Estado, 2001.

SAYEG HELÚ, Jorge. El constitucionalismo social mexicano, la integración constitucional de México (1808-1988). México-DF: Fondo de Cultura Económico, 1996.

VALDÉS, Ernesto Garzon. Derecho, ética y política. Centro de estudios constitucionales: Madrid, 1993.

VALDÉS, Ernesto Garzon.Constitución y democracia en américa latina. In: Anuario de derecho constitucional latinoamericano. edición 2000. Buenos Ayres: Fundación Konrad Adenauer, 2000.

WOLKMER, Antonio Carlos. Constitucionalismo e direitos sociais no Brasil. Acadêmica: 1989. WOLKMER, Antonio Carlos.. História do direito no Brasil. 5. ed. Forense: Rio de Janeiro, 2012.

Recebido em: 01.06.2018 / Revisões requeridas em: 20.07.2019 / Aprovado em: 28.11.2019 / Publicado em: 28.03.2020

\section{COMO FAZER REFERÊNCIA AO ARTIGO (ABNT):}

RAFAELLI, Samuel Mânica; WOLKMER, Antonio Carlos. Análise crítica do ideário liberal na trajetória do constitucionalismo latino-americano. Revista Eletrônica do Curso de Direito da UFSM, Santa Maria, RS, v. 15, n. 1, e32879, jan./abr. 2020. ISSN 1981-3694. DOI: http://dx.doi.org/10.5902/1981369432879. Disponível em: https://periodicos.ufsm.br/revistadireito/article/view/32879 Acesso em: dia mês. ano.

Direitos autorais 2020 Revista Eletrônica do Curso de Direito da UFSM

Editores responsáveis: Rafael Santos de Oliveira e Angela Araujo da Silveira Espindola

Esta obra está licenciada com uma Licença Creative Commons Atribuição-NãoComercial-SemDerivações 4.0 Internacional. 


\section{SOBRE OS AUTORES}

SAMUEL MÂNICA RADAELLI

Possui graduação em Direito pela Universidade Regional do Noroeste do Estado do Rio Grande do Sul- UNIJUI (2005), mestrado em Direito Público pela Universidade do Vale do Rio dos Sinos- UNISINOS (2007), doutorado em Direito pela UFSC. Atualmente é professor do Instituto Federal do Paraná-IFPR e advogado. Tem experiência na área de Direito, com ênfase em Ciência Política, Direito Constitucional, Filosofia e Sociologia Jurídica, atuando principalmente nos seguintes temas: teoria constitucional, alteridade, direitos humanos.

\section{ANTONIO CARLOS WOLKMER}

Formado em Direito pela Universidade do Vale do Rio dos Sinos (UNISINOS, 1977). Especialista em Metodologia do Ensino Superior pela UNISINOS (1980). Mestre em Ciência Política pela Universidade Federal do Rio Grande do Sul (UFRGS, 1983) e Doutor em Direito pela Universidade Federal de Santa Catarina (UFSC, 1992). Professor Titular Aposentado no Curso de PósGraduação em Direito da Universidade Federal de Santa Catarina (UFSC) e Docente Permanente no Programa de PósGraduação em Direito e Sociedade do UNILASALLE-RS. Coordenador e Professor do Mestrado em Direitos Humanos e Sociedade da UNESC. Consultor Ad Hoc da CAPES e do CNPq, sendo desta pesquisador nível 1-A. Coordenador do Programa de Pós-Graduação em Direito da UFSC entre 2007-2011. Membro do Comitê Assessor para a área do Direito do Comitê de Assessoramento de Antropologia, Arqueologia, Ciência Política, Direito, Relações Internacionais e Sociologia - CA-CS, do CNPq (2009-2012). Membro do Comitê Científico do Institut International d'Études et de Recherches sur les Biens Communs, Paris/Napoli. e do Grupo de Trabajo CLACSO: "Pensamiento Jurídico Crítico". 2016-2018 (Buenos Aires/Equador). Socio da Sociedad Argentina de Sociología Jurídica (SASJU). Member International Political Science Association (IPSA, Canada), bem como do Instituto Internacional de Derecho y Sociedad - IIDS (Lima, Perú), e do Research Committee on Sociology of Law (RCSL). Membro da Associação Brasileira de Filosofia e Sociologia do Direito (ABRAFI), do Instituto Brasileiro de História do Direito (IBHD), da Rede para o Constitucionalismo Democrático Latino-Americano e Associado Honorário do Conselho Nacional de Pesquisa e Pós-Graduação em Direito (CONPEDI). Membro vitalício da Academia Catarinense de Letras Jurídicas (ACALEJ Cadeira $\left.n^{\circ} 10\right)$. Coordenador do NEPE/UFSC - Núcleo de Estudos e Práticas Emancipatórias); e do NUPEC - Núcleo de Pesquisa em Direitos Humanos e Cidadania, UNESC-SC. Prêmio Pesquisador Destaque do Direito nos 50 anos Comemorativos da UFSC, em 2010. Professor colaborador permanente do Master y Doctorado en Derechos Humanos y Interculturalidad de la Universidad Pablo de Olavide (Sevilha, Espanha), de la Maestría en Derechos Humanos de la Universidad A. San Luis Potosí (Mexico) y del Doctorado en Derecho - Modalidad Especial - de la Universidad de Buenos Aires (Argentina) y del Diplomado en Antropología Jurídica y Derechos Indígenas, de la Universidad de Chile, y del Doctorado en Derecho, de la Universidad Libre Bogotá, Colombia. Professor convidado em diversas universidades e programas de pós-graduação no exterior: Espanha, Itália, México, Perú, Colômbia, Argentina, Chile, Equador,Venezuela, Costa Rica e Porto Rico. Tem experiência na área de Direito, com ênfase em Teoria do Direito, atuando principalmente nos seguintes temas: Sociologia Jurídica, Pluralismo Jurídico, Historia do Direito, Filosofia do Direito e Direitos Humanos, Cultura Jurídica e Constitucionalismo Latino-Americano. 